\title{
BMJ Open Cross-sectional study examining whether the extent of first-contact access to primary care differentially benefits those with certain personalities to receive preventive services
}

\author{
Nancy Pandhi, ${ }^{1,2}$ Jessica R Schumacher, ${ }^{3}$ Carolyn T Thorpe, ${ }^{4,5}$ \\ Maureen A Smith ${ }^{1,2,3,6}$
}

To cite: Pandhi N, Schumacher JR, Thorpe CT, et al. Cross-sectional study examining whether the extent of first-contact access to primary care differentially benefits those with certain personalities to receive preventive services. $B M J$ Open 2016;6: 0009738. doi:10.1136/bmjopen-2015009738

- Prepublication history for this paper is available online. To view these files please visit the journal online (http://dx.doi.org/10.1136/ bmjopen-2015-009738).

Received 31 August 2015 Revised 29 January 2016 Accepted 1 February 2016

CrossMark

For numbered affiliations see end of article.

\section{Correspondence to} Dr Nancy Pandhi; nancy.pandhi@fammed.wisc. edu

\section{ABSTRACT}

Objective: The extent of first-contact access to primary care (ie, easy availability when needed) is associated with receiving recommended preventive services. Whether this access benefits patients at risk of preventive services underutilisation, such as those with certain personality characteristics, is unclear.

Setting: Secondary analysis of the 2003-2006 round of the Wisconsin Longitudinal Study.

Participants: 6975 respondents who reported a usual provider whose specialty was internal medicine or family medicine. Those reporting not visiting a medical provider in the past 12 months, and those who were uninsured were excluded.

\section{Primary outcome measures: Receiving}

mammography, cholesterol testing and influenza vaccination. Adjusted predicted probabilities (aPP) of receiving these services were analysed stratified by personality characteristics overall, and if significant, then interacted with first-contact access.

Results: Lower conscientiousness as compared with higher conscientiousness predicted less of all 3 preventive services; mammography (aPP 80\%; 95\% Cl (77\% to $83 \%)$ vs aPP $85 \%$; $(95 \%$ Cl $82 \%$ to $87 \%)$ ), cholesterol testing (88\%; (85\% to $90 \%$ ) vs $93 \%(91 \%$ to $94 \%)$, and influenza vaccination $(62 \%$; $(59 \%$ to $64 \%$ ) vs $66 \%$; $(63 \%$ to $68 \%))$. Lower agreeableness as compared with higher agreeableness predicted less mammography $(77 \%$; (73\% to $81 \%)$ vs $84 \%$; $(82 \%$ to $87 \%)$ ) and less influenza vaccination (59\%; (56\% to $62 \%$ ) vs $65 \%$; $(63 \%$ to $68 \%))$. Lower extraversion predicted less cholesterol testing (88\%; (86\% to $91 \%$ ) vs $(92 \%$; $(90 \%$ to $94 \%))$. Lower openness to experience predicted less influenza vaccination $(59 \%$; (56\% to $63 \%)$ vs (68\%; $(65 \%$ to $70 \%))$. For agreeableness, these differences in receiving preventive services did not persist when first-contact access to primary care was present.

Conclusions: Certain personality characteristics predicted receiving less preventive care services. For those with less agreeableness, improved first-contact access to primary care mitigated this effect. If these results are replicated in other studies, primary care

\section{Strengths and limitations of this study}

- This article provides evidence suggesting that first-contact access to primary care can diminish the negative influence of certain personality characteristics on receiving preventive health services.

- This study adds to a growing body of literature demonstrating associations between certain personality characteristics and health behaviours.

- One strength of the study is the large sample size and high response rate; however, generalisability may be limited, as this is a cohort study of insured older adults who graduated from high school in a single state in the USA.

offices seeking to improve population health through receiving preventive services should prioritise increasing their first-contact accessibility.

\section{INTRODUCTION}

Receiving preventive services such as cancer screening, immunisations and cholesterol screening is well known to reduce premature mortality. ${ }^{1}$ Despite enormous investment in the promotion of prevention during the past two decades in the USA, however, gains in use of preventive services have been limited. ${ }^{2-4}$ Interestingly, the extent of firstcontact access defined as the availability and accessibility of medical services when needed, ${ }^{5}$ (eg, availability of medical advice by telephone) is associated with receiving improved preventive service among those with a usual primary care provider. ${ }^{6-8}$ What is less clear, though, is whether the extent of first-contact access to primary care can improve the receipt of preventive care 
among patients at risk of underusing these services despite having a usual primary care provider. This knowledge is important given the increased focus on primary care accountability for achieving care quality and incentives such as pay-for-performance that reward gains in receiving preventive service. If first-contact access to primary care differentially benefits certain individuals within a patient population, then targeted practice interventions that outreach to this group become a promising primary care redesign strategy.

One barrier to providing preventive care is that individuals with certain personality characteristics are less likely to engage in preventive health behaviours, including medication adherence, ${ }^{9-11}$ appropriate amounts of substance use, ${ }^{12-14}$ and healthy eating. ${ }^{15} 16$ There has been less study of the association between personality characteristics and receiving preventive services. This gap is surprising given the strong linkage between personality characteristics and longevity, ${ }^{17}$ and that other individual factors such as gender, age and race/ethnicity are well studied for their influence on preventive health behaviours and usage. There has been growing interest in incorporating patient personality into delivery system interventions ${ }^{18}{ }^{19}$ facilitated by the existence of a wellvalidated personality screening tool that is stable across age groups $^{20}$ and multiple cultures. ${ }^{21}$ This screening tool, the Five-Factor Model of personality, ${ }^{22}$ classifies personality according to the degree of five characteristics: neuroticism, extraversion, openness to experience, agreeableness, and conscientiousness. Investigators studying personality characteristics and receiving preventive services to date have primarily focused on the personality characteristic of conscientiousness. This research reveals that women with greater levels of conscientiousness received increased cervical and breast cancer screening. ${ }^{23-25}$ A single study, examining only the personality characteristic of neuroticism, found it to be associated with increased influenza vaccination. ${ }^{26}$

The purpose of this study is to investigate the influence of personality characteristics on receiving guideline appropriate of mammography, cholesterol testing and influenza vaccination in an older adult population receiving primary care. We also investigated the influence of first-contact access to primary care on receiving these services by individuals with these personality characteristics.

\section{METHODS}

\section{Sample}

The sample was drawn from the 2003 to 2006 round of the combined telephone and mail survey from the Wisconsin Longitudinal Study (WLS), a long-term cohort study of a one-third random sample of individuals who graduated from Wisconsin high schools in 1957 ( $\mathrm{N}=10317)$, and their randomly selected siblings $(\mathrm{N}=7928)$. The response rate among survivors for the telephone survey was $80 \%$ among graduates and $64 \%$ for siblings. The response rate for the mailed survey was $76 \%$ among graduates and 60\% among siblings. This study has had continually high response rates due to a history of 'good will' with the sample. ${ }^{27}$

The University of Wisconsin-Madison Education and Social/Behavioral Science Institutional Review Board granted approval for this study.

We restricted the sample to include only respondents who reported a usual provider whose specialty was internal medicine or family medicine $(76 \%)$. We then excluded respondents who reported not visiting a medical provider in the past 12 months $(6 \%)$, and those who were uninsured $(2 \%)$. The final sample consisted of 6975 older adult respondents.

\section{Variables/measures}

The primary outcome variables for receiving preventive services were generated from yes/no questions that asked respondents to report on their receipt in the past 12 months of three services, chosen because guidelines in place at the time of the survey recommended that they be performed annually for this population. ${ }^{28-31}$ Respondents were asked, 'In the last 12 months, have you had (1) a mammogram; (2) a cholesterol test; and/ or (3) a flu shot?'. Mammography was conducted in women aged 40 years or older, receiving influenza vaccination in those aged 50 years or older, and annual cholesterol testing in those reporting atherosclerotic vascular disease conditions (high blood pressure, coronary heart disease/myocardial infarction, circulation problems, stroke, high cholesterol), and diabetes.

The Five-Factor Model of personality was used for assessing personality. ${ }^{22}$ In the WLS, a six-question scale was asked for each personality characteristic except neuroticism, where the scale included five questions. Response categories for each question ranged from (1) agree strongly to (6) disagree strongly. These 29 items are a subset of the BFI-54. ${ }^{32}$ Responses were summed for each characteristic, and a dichotomous categorical variable was created using those in the top tertile $(0)$ versus those in the bottom tertile (1). Those in the middle tertile were not used in analysis. This strategy was used in order to clearly differentiate those who had high agreement with a personality characteristic from those who had low agreement.

Similar to prior published work, ${ }^{78}$ first-contact access was assessed using eight items from the validated access to care subscale of the Group Health Association of America's Consumer Satisfaction Survey. ${ }^{33}$ These items began with the stem, 'Thinking about your own health care, how would you rate...' Areas assessed were the (1) convenience of the location of your doctor's office, (2) hours when the doctor's office is open, (3) arrangements for making appointments for medical care by phone, (4) length of time spent waiting at the office to see the doctor, (5) length of time waiting between making an appointment for routine care and the day of the visit, (6) availability of medical information or advice 
by phone, (7) ease of seeing the doctor of your choice and (8) amount of time you have with doctors and staff during a visit. The original response categories were excellent, very good, good, fair, or poor. Responses of excellent or very good were considered to be indicative of perceiving that access in an area was satisfactory; thus, those answering very good or excellent to all eight questions were considered to have first-contact accessibility.

Covariates known to predict healthcare usage ${ }^{34}$ were included in all models as categorical variables. These were age $(<60,60-64,65-69,70+$ years), gender (except for the model predicting mammography), marital status (married, separated/divorced, widowed, never married), education (high school or less, some college, college, postgraduate), total household income ( $<$ US $\$ 30000$, US $\$ 30$ 000-US\$44 999, US\$45 000-US\$59 999, US\$60 000US $\$ 74999$, $\geq$ US $\$ 75000$ and missing), type of health insurance (private, Medicare and other private, Medicare or other public), and a count of self-reported chronic conditions $(0-1,2,3, \geq 4)$.

\section{Statistical analysis}

Data were analysed using Stata V.11.1. First, percentages for categorical variables were calculated. Then, unadjusted and adjusted logistic regression models were estimated comparing the effect of each personality characteristic (highest tertile vs lowest tertile) on receiving the three preventive services. Statistical significance was determined at $\mathrm{p}<0.05$. After estimation, adjusted average predicted probabilities of receiving preventive service were calculated using the recycled predictions approach using the margins command in Stata. Ninety-five per cent CIs were calculated using a robust estimate of the variance that allowed for clustering of siblings within families. For models where there was a significant effect of personality on receiving preventive service, we then examined the effect of each personality characteristic for those who did and did not have first-contact access. We did this by estimating adjusted multivariable logistic regression models that included each preventive service as the dependent variable and including as independent variables first-contact access, the personality characteristic, first-contact access interacted with the personality characteristic, and covariates. Statistical significance was reported through examining the $p$ value of the interaction term which tested the hypothesis of whether firstcontact access to primary care changed the relationship of specific personality characteristics to receiving preventive service.

\section{RESULTS}

Descriptive characteristics of this cohort of older adults who are seen in primary care clinics are presented in table 1. Seventeen per cent $(\mathrm{N}=1193)$ of these individuals reported first-contact access. Receiving preventive services was high in the overall population. Eighty-two
Table 1 Key demographic characteristics of 2003-2006 Wisconsin Longitudinal Study respondents $(\mathrm{N}=6975)$

\begin{tabular}{|c|c|c|}
\hline & $\mathbf{N}$ & Per cent \\
\hline \multicolumn{3}{|l|}{ Age (years) } \\
\hline$<60$ & 583 & 8 \\
\hline $60-64$ & 3674 & 53 \\
\hline $65-69$ & 2149 & 31 \\
\hline$\geq 70$ & 569 & 8 \\
\hline \multicolumn{3}{|l|}{ Sex } \\
\hline Male & 3227 & 46 \\
\hline Female & 3748 & 54 \\
\hline \multicolumn{3}{|l|}{ Marital status } \\
\hline Married & 5585 & 80 \\
\hline Separated or divorced & 605 & 9 \\
\hline Widowed & 533 & 8 \\
\hline Never married & 250 & 4 \\
\hline \multicolumn{3}{|l|}{ Educational attainment } \\
\hline High school or less & 3671 & 53 \\
\hline Some college & 1113 & 16 \\
\hline College & 1044 & 15 \\
\hline Postgraduate & 1085 & 16 \\
\hline \multicolumn{3}{|l|}{ Total household income (US\$) } \\
\hline$<30000$ & 1282 & 18 \\
\hline $30000-44999$ & 1186 & 17 \\
\hline $45000-59999$ & 1034 & 15 \\
\hline $60000-74999$ & 862 & 12 \\
\hline$\geq 75000$ & 2311 & 33 \\
\hline Missing & 300 & 4 \\
\hline \multicolumn{3}{|l|}{ Health insurance } \\
\hline Private & 3903 & 56 \\
\hline Medicare and other private & 2342 & 34 \\
\hline Medicare or other public & 730 & 10 \\
\hline \multicolumn{3}{|l|}{ Chronic conditions* ${ }^{*}$} \\
\hline $0-1$ & 1035 & 15 \\
\hline 2 & 1092 & 16 \\
\hline 3 & 1231 & 18 \\
\hline 4 or more & 3617 & 52 \\
\hline \multicolumn{3}{|c|}{ Received a mammogram in past 12 months $(\mathrm{N}=3691) \dagger$} \\
\hline Yes & 3037 & 82 \\
\hline No & 654 & 18 \\
\hline \multicolumn{3}{|c|}{ Received a cholesterol test in past 12 months $(\mathrm{N}=5188) \ddagger$} \\
\hline Yes & 4677 & 90 \\
\hline No & 511 & 10 \\
\hline \multicolumn{3}{|c|}{$\begin{array}{l}\text { Received an influenza vaccination in past } 12 \text { months } \\
(\mathrm{N}=6844) \S\end{array}$} \\
\hline Yes & 4283 & 63 \\
\hline No & 2561 & 37 \\
\hline
\end{tabular}

*The following 22 chronic conditions were measured in this count: asthma, bronchitis/emphysema, serious back trouble, circulation problems, kidney/bladder problems, ulcer, allergies, multiple sclerosis, high blood pressure, diabetes, cancer, coronary heart disease/myocardial infarction, stroke, arthritis, pain and stiffness in the joints, mental illness, chronic sinusitis, fibromyalgia, high cholesterol, irritable bowel syndrome, osteoporosis and prostate problems.

†Mammogram screening was examined in women aged 40 years or older.

$\ddagger$ Cholesterol testing was examined in those reporting atherosclerotic vascular disease conditions (high blood pressure, coronary heart disease/myocardial infarction, circulation problems, stroke, high cholesterol) and diabetes.

$\S$ Influenza vaccination was examined in those aged 50 years or older. 
per cent of eligible adults reported receiving a mammogram, $90 \%$ reported receiving a cholesterol test, and $63 \%$ reported receiving an influenza vaccination in the past 12 months.

Predicted probabilities of receiving mammography according to each of the personality characteristics and by first-contact access status are shown in table 2. In adjusted models for the overall population, the two personality characteristics that were significant for differences in receiving mammography, overall, were agreeableness and conscientiousness. Seventy-seven per cent of those with low agreeableness $(95 \%$ CI $73 \%$ to $81 \%$ ) received a mammogram versus $84 \%$ of those with high agreeableness (95\% CI $82 \%$ to $87 \%$ ). Similarly, $80 \%$ of those with low conscientiousness $(95 \%$ CI $77 \%$ to $83 \%$ ) received a mammogram versus $85 \%$ of those with high conscientiousness (95\% CI $82 \%$ to $87 \%$ ). This significant difference in receiving mammograms persisted for those without first-contact access for agreeableness $\quad$ (low agreeableness $=$ adjusted predicted probability (aPP), $75 \% ; \quad 95 \%$ CI $71 \%$ to $79 \%$; high agreeableness $=\mathrm{aPP}, 84 \% ; 95 \%$ CI $81 \%$ to $87 \%$ ). However, for participants with first-contact access, mammography use remained consistently high regardless of the level of agreeableness (low agreeableness $=\mathrm{aPP}, 89 \%$; 95\% CI $81 \%$ to $97 \%$; high agreeableness=aPP, $85 \%$; $95 \%$ CI $80 \%$ to $89 \%$ ). Receiving mammography did not differ according to first-contact access and conscientiousness $(\mathrm{p}=0.44)$.

Conscientiousness and extraversion were the only personality characteristics found to predict differences in receiving cholesterol testing (table 3). In adjusted models overall, $88 \%$ of those with low conscientiousness received a cholesterol test (95\% CI $85 \%$ to $90 \%)$ as compared to $93 \%$ of highly conscientious individuals who received a cholesterol test (95\% CI $91 \%$ to 94\%). Similarly, $88 \%$ of those with low extraversion received a cholesterol test (95\% CI $86 \%$ to $91 \%$ ) as compared to $92 \%$ of those with high extraversion (95\% CI $90 \%$ to $94 \%)$. Cholesterol testing did not differ for either conscientiousness $(\mathrm{p}=0.94)$ or extraversion $(\mathrm{p}=0.11)$ according to the extent of first-contact access to primary care.

As shown in table 4, after adjustment, lower agreeableness, conscientiousness and openness to experience was associated with significant decreased influenza vaccination in the overall population. Influenza vaccination was received by $59 \%$ of those in the lowest tertile of agreeableness (95\% CI $56 \%$ to $62 \%$ ) vs $65 \%$ of those in the highest tertile of agreeableness (95\% CI $63 \%$ to $68 \%)$. Sixty-two per cent of those in the lowest tertile of conscientiousness $(95 \%$ CI $59 \%$ to $64 \%$ ) received influenza vaccination versus $66 \%$ of those in the highest tertile of this characteristic (95\% CI 63\% to 68\%). Fifty-nine per cent of those in the lowest tertile of openness to experience (95\% CI $56 \%$ to $63 \%$ ) received influenza vaccination as compared to $68 \%$ of those in the highest tertile of openness to experience (95\% CI $65 \%$ to $70 \%$ ). For the agreeableness personality characteristic

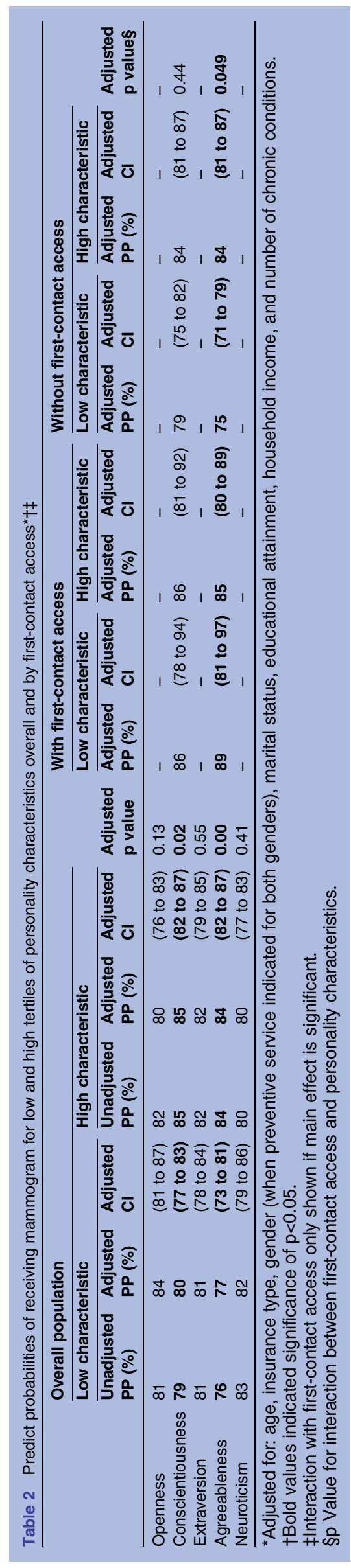


Table 3 Predicted probabilities of cholesterol test receipt for low and high tertiles of personality characteristics overall and by first-contact access ${ }^{*} \ddagger \ddagger$

\begin{tabular}{|c|c|c|c|c|c|c|c|c|c|c|c|c|c|c|c|c|}
\hline & \multicolumn{6}{|c|}{ Overall population } & \multirow[b]{3}{*}{$\begin{array}{l}\text { Adjusted } \\
\mathrm{Cl}\end{array}$} & \multicolumn{4}{|c|}{ With first-contact access } & \multicolumn{4}{|c|}{ Without first-contact access } & \multirow[b]{3}{*}{$\begin{array}{l}\text { Adjusted } \\
\text { p value§ }\end{array}$} \\
\hline & \multicolumn{3}{|c|}{ Low characteristic } & \multicolumn{3}{|c|}{ High characteristic } & & \multicolumn{2}{|c|}{ Low characteristic } & \multicolumn{2}{|c|}{ High characteristic } & \multicolumn{2}{|c|}{ Low characteristic } & \multicolumn{2}{|c|}{ High characteristic } & \\
\hline & $\begin{array}{l}\text { Unadjusted } \\
\text { PP (\%) }\end{array}$ & $\begin{array}{l}\text { Adjusted } \\
\text { PP (\%) }\end{array}$ & $\begin{array}{l}\text { Adjusted } \\
\mathrm{p} \text { value }\end{array}$ & $\begin{array}{l}\text { Adjusted } \\
\mathrm{Cl}\end{array}$ & $\begin{array}{l}\text { Unadjusted } \\
\text { PP (\%) }\end{array}$ & $\begin{array}{l}\text { Adjusted } \\
\text { PP (\%) }\end{array}$ & & $\begin{array}{l}\text { Adjusted } \\
\text { PP (\%) }\end{array}$ & $\begin{array}{l}\text { Adjusted } \\
\mathrm{Cl}\end{array}$ & $\begin{array}{l}\text { Adjusted } \\
\text { PP (\%) }\end{array}$ & $\begin{array}{l}\text { Adjusted } \\
\mathrm{Cl}\end{array}$ & $\begin{array}{l}\text { Adjusted } \\
\text { PP (\%) }\end{array}$ & $\begin{array}{l}\text { Adjusted } \\
\mathrm{Cl}\end{array}$ & $\begin{array}{l}\text { Adjusted } \\
\text { PP (\%) }\end{array}$ & $\begin{array}{l}\text { Adjusted } \\
\mathrm{Cl}\end{array}$ & \\
\hline Openness & 88 & 88 & (86 to 91 ) & 91 & 91 & (88 to 93 ) & 0.23 & - & - & - & - & - & - & - & - & - \\
\hline Conscientiousness & 88 & 88 & (85 to 90 ) & 92 & 93 & (91 to 94 ) & 0.00 & 90 & (84 to 95 ) & 94 & (90 to 97 ) & 87 & (84 to 89 ) & 92 & (90 to 94 ) & 0.94 \\
\hline Extraversion & 89 & 88 & (86 to 91 ) & 92 & 92 & (90 to 94 ) & 0.01 & 93 & (88 to 97 ) & 91 & (87 to 95 ) & 88 & (85 to 90 ) & 92 & (90 to 94 ) & 0.11 \\
\hline Agreeableness & 90 & 89 & (87 to 91 ) & 91 & 91 & (89 to 93 ) & 0.13 & - & - & - & - & - & - & - & - & - \\
\hline Neuroticism & 92 & 92 & (90 to 94 ) & 91 & 91 & (89 to 93 ) & 0.71 & - & - & - & - & - & - & - & - & - \\
\hline
\end{tabular}

*Adjusted for: age, insurance type, gender (when preventive service indicated for both genders), marital status, educational attainment, household income, and number of chronic conditions. †Bold values indicated significance of $p<0.05$.

fInteraction with first-contact access only shown if main effect is significant.

$\S p$ Value for interaction between first-contact access and personality characteristics.

Table 4 Predicted probabilities of receiving influenza vaccination for low and high tertiles of personality characteristics overall and by first-contact access ${ }^{*} \dagger \ddagger$

\begin{tabular}{|c|c|c|c|c|c|c|c|c|c|c|c|c|c|c|c|c|}
\hline & \multicolumn{6}{|c|}{ Overall population } & \multirow[b]{3}{*}{$\begin{array}{l}\text { Adjusted } \\
\text { p value }\end{array}$} & \multicolumn{4}{|c|}{ With first-contact access } & \multicolumn{4}{|c|}{ Without first-contact access } & \multirow[b]{3}{*}{$\begin{array}{l}\text { Adjusted } \\
\text { p value§ }\end{array}$} \\
\hline & \multicolumn{3}{|c|}{ Low characteristic } & \multicolumn{3}{|c|}{ High characteristic } & & \multicolumn{2}{|c|}{ Low characteristic } & \multicolumn{2}{|c|}{ High characteristic } & \multicolumn{2}{|c|}{ Low characteristic } & \multicolumn{2}{|c|}{ High characteristic } & \\
\hline & $\begin{array}{l}\text { Unadjusted } \\
\text { PP (\%) }\end{array}$ & $\begin{array}{l}\text { Adjusted } \\
\text { PP (\%) }\end{array}$ & $\begin{array}{l}\text { Adjusted } \\
\mathrm{Cl}\end{array}$ & $\begin{array}{l}\text { Unadjusted } \\
\text { PP (\%) }\end{array}$ & $\begin{array}{l}\text { Adjusted } \\
\text { PP (\%) }\end{array}$ & $\begin{array}{l}\text { Adjusted } \\
\mathrm{Cl}\end{array}$ & & $\begin{array}{l}\text { Adjusted } \\
\text { PP (\%) }\end{array}$ & $\begin{array}{l}\text { Adjusted } \\
\mathrm{Cl}\end{array}$ & $\begin{array}{l}\text { Adjusted } \\
\text { PP (\%) }\end{array}$ & $\begin{array}{l}\text { Adjusted } \\
\mathrm{Cl}\end{array}$ & $\begin{array}{l}\text { Adjusted } \\
\text { PP (\%) }\end{array}$ & $\begin{array}{l}\text { Adjusted } \\
\mathrm{Cl}\end{array}$ & $\begin{array}{l}\text { Adjusted } \\
\text { PP (\%) }\end{array}$ & $\begin{array}{l}\text { Adjusted } \\
\mathrm{Cl}\end{array}$ & \\
\hline Openness & 59 & 59 & (56 to 63 ) & 68 & 68 & (65 to 70$)$ & 0.00 & 68 & (60 to 75$)$ & 75 & (70 to 81 ) & 57 & (54 to 61$)$ & 66 & (63 to 69 ) & 0.95 \\
\hline Conscientiousness & 62 & 62 & (59 to 64 ) & 65 & 66 & (63 to 68 ) & 0.04 & 68 & (61 to 75 ) & 68 & (62 to 73 ) & 61 & (58 to 64 ) & 65 & (62 to 68 ) & 0.39 \\
\hline Extraversion & 62 & 62 & (59 to 65 ) & 63 & 64 & (61 to 66 ) & 0.48 & - & - & - & - & - & - & - & - & - \\
\hline Agreeableness & 59 & 59 & (56 to 62$)$ & 65 & 65 & (63 to 68 ) & 0.00 & 70 & (63 to 78 ) & 68 & (63 to 73 ) & 57 & (54 to 60$)$ & 65 & (62 to 68 ) & 0.00 \\
\hline Neuroticism & 63 & 65 & (62 to 68$)$ & 63 & 61 & (58 to 64 ) & 0.12 & - & - & - & - & - & - & - & - & - \\
\hline
\end{tabular}


only, there were significant differences $(\mathrm{p}=0.00)$ in influenza vaccination for those with and without first-contact access. Sixty-eight per cent of those with first-contact access and high agreeableness received influenza vaccination (95\% CI $63 \%$ to $73 \%$ ) versus $65 \%$ of those without first-contact access and high agreeableness (95\% CI $62 \%$ to $68 \%$ ). Seventy per cent of those with first-contact access and low agreeableness received influenza vaccination (95\% CI $63 \%$ to $78 \%$ ) versus $57 \%$ of those without first-contact access and low agreeableness (95\% CI 54\% to $60 \%)$.

\section{DISCUSSION}

In this sample of older adults with a usual primary care provider, we found that four of five personality characteristics were associated significantly with receiving mammography, cholesterol screening or influenza vaccination. Conscientiousness was the only personality characteristic that was associated significantly with receiving all three of these preventive services. Our findings are consistent with other studies that have found conscientiousness to be associated with increased preventive screening. ${ }^{23-25}$ We also found that lower agreeableness was associated with decreased mammography and influenza vaccination. Lower extraversion was associated with receiving less cholesterol testing, and less openness to experience was associated with decreased influenza vaccination. Neuroticism was not associated with any significant differences in receiving preventive services in the overall study population.

Interestingly, for participants who reported firstcontact access to primary care, there were no significant differences in receiving preventive services between those with high and low levels of agreeableness. Indeed, personality continued to predict receiving preventive services only among participants without first-contact access to primary care. This pattern of first-contact access negating the significant association between personality and preventive services use was consistent for both mammography and influenza vaccination. This finding, if borne out in future research studies, suggests that first-contact access to primary care may benefit certain patient subpopulations with personality characteristics that might inhibit receipt of preventive services. In particular, those who are less agreeable may benefit from first-contact access to primary care. These findings also suggest that personality may help compensate for poor first-contact access to primary care among certain subpopulations whose personality characteristics increase the likelihood of receiving preventive services.

Given efforts to provide access to preventive services outside of primary care offices, such as vaccinations through pharmacies ${ }^{30} 35$ and mammography selfscheduling, ${ }^{36}$ understanding which subsets of patients benefit from first-contact access to a primary care is critical. Our findings add to the literature supporting the importance of first-contact access to primary care for receiving improved preventive services. ${ }^{6-8}$ Additionally, they suggest that there may be patients with certain personality characteristics in whom receiving preventive services may improve by having easily available primary care.

This study adds to a growing body of literature demonstrating associations between certain personality characteristics and health behaviours. ${ }^{9-16} 23-2537$ As preventive care becomes an increasing priority and primary care is redesigned to shift from being acute office visit based to a medical home model that takes on accountability for the health of a population of patients, novel approaches to receiving improved preventive service are needed. Further, delivery system-based research that uses personality screening as a tool to tailor preventive health interventions is warranted. In particular, a health delivery system might consider administering a brief personality screening tool in order to match a new patient with a primary care clinic that has the access to care that can best support individualised patient needs. Additionally, personality screening might be examined as a tool to target outreach and patient education to certain subpopulations.

There are several limitations to this study. First, this is a cohort study of insured older adults who graduated from high school in Wisconsin, and their siblings, not a random national sample. Therefore, generalisability of our results may be limited. They may, however, extend to other countries that do not face the issues caused by insurance in the USA, but also have access difficulties. Given that the personality tool we used is validated across multiple cultures, ${ }^{21}$ further research should examine how personality characteristics, receiving preventive services, and first-contact access to primary care are associated in more geographically and racially diverse populations. Next, the individuals in our sample were primarily above the age 60 years, and we studied only the receipt of three preventive services. Further confirmation of our results should be performed in samples with adults of younger and older ages, and include receiving other preventive services. Last, we used self-reported receipt of preventive services and firstcontact access to primary care, which may result in under-reporting or over-reporting. It is unknown whether reporting would differ in individuals with certain personality characteristics. Correlations between healthcare use assessed through self-report and medical record review, however (eg, cancer screening), has been shown to be moderate to high. ${ }^{38}$

In conclusion, our findings suggest that low levels of the personality characteristics of agreeableness, extraversion, conscientiousness and openness to experience are associated with reduced preventive care use. For patients with first-contact access to primary care and low agreeableness, preventive care use was similar regardless of personality. These findings suggest that having firstcontact access to a primary care home may improve receiving preventive service in patients with personality 
characteristics typically associated with lower preventive service usage rates. If these results are replicated in other studies, primary care offices seeking to improve preventive services received in their total patient population may wish to prioritise increasing first-contact access to care for less agreeable patients who are not receiving recommended preventive services.

\section{Author affiliations}

${ }^{1}$ Department of Family Medicine and Community Health, University of Wisconsin School of Medicine and Public Health, Madison, Wisconsin, USA ${ }^{2}$ Department of Population Health Sciences, Health Innovation Program, University of Wisconsin School of Medicine and Public Health, Madison, Wisconsin, USA

${ }^{3}$ Department of Surgery, University of Wisconsin School of Medicine and Public Health, Madison, Wisconsin, USA

${ }^{4}$ Department of Pharmacy and Therapeutics, University of Pittsburgh Schoo of Pharmacy, Philadelphia, Pennsylvania, USA

${ }^{5}$ Veterans Affairs Pittsburgh Healthcare System, Health Services Research and Development, Pittsburgh, Pennsylvania, USA

${ }^{6}$ Department of Population Health Sciences, University of Wisconsin School of Medicine and Public Health, Madison, Wisconsin, USA

Acknowledgements The authors thank Zaher Karp and Natalie Wietfeldt for editing and formatting assistance.

Contributors NP conceived of the study design, performed analysis and interpretation of the data, drafted and critically revised the manuscript for important intellectual content, and approved the final version. JRS contributed to interpretation of the data; critically revised the manuscript for important intellectual content, and approved the final version. CTT contributed to critically revising the manuscript for important intellectual content, and approved the final version. MAS contributed to the study design, analysis and interpretation of the data, critically revised the manuscript for important intellectual content, and approved the final version.

Funding This work was supported by the Clinical and Translational Science Award (CTSA) programme, previously through the National Center for Research Resources (NCRR) grant 1UL1RR025011, and now by the National Center for Advancing Translational Sciences (NCATS), grant 9U54TR000021. The content is solely the responsibility of the authors, and does not necessarily represent the official views of the $\mathrm{NIH}$, the Department of Veterans Affairs or the USA government. In addition, NP was supported by a National Institute on Aging Mentored Clinical Scientist Research Career Development Award, grant number I K08 AG029527. This project was also supported by the University of Wisconsin Carbone Cancer Center (UWCCC) Support Grant from the National Cancer Institute, grant number P30 CA014520. Additional support was provided by the UW School of Medicine and Public Health from the Wisconsin Partnership Program.

Competing interests None declared.

Ethics approval The University of Wisconsin-Madison Education and Social/ Behavioral Science Institutional Review Board.

Provenance and peer review Not commissioned; externally peer reviewed.

Data sharing statement No additional data are available.

Open Access This is an Open Access article distributed in accordance with the Creative Commons Attribution Non Commercial (CC BY-NC 4.0) license, which permits others to distribute, remix, adapt, build upon this work noncommercially, and license their derivative works on different terms, provided the original work is properly cited and the use is non-commercial. See: http:// creativecommons.org/licenses/by-nc/4.0/

\section{REFERENCES}

1. Farley TA, Dalal MA, Mostashari F, et al. Deaths preventable in the U.S. by improvements in use of clinical preventive services. Am J Prev Med 2010;38:600-9.
2. Melnikow J, Kohatsu ND, Chan BK. Put prevention into practice: a controlled evaluation. Am J Public Health 2000;90:1622-5.

3. Yarnall KS, Ostbye T, Krause KM, et al. Family physicians as team leaders: "time" to share the care. Prev Chronic Dis 2009;6:A59.

4. Richardson L, Rim S, Plescia M. Vital signs: breast cancer screening among women aged 50-74 years-United States, 2008. MMWR Morb Mortal Wkly Rep 2010;59:813-16.

5. Ferrante JM, Balasubramanian BA, Hudson SV, et al. Principles of the patient-centered medical home and preventive services delivery. Ann Fam Med 2010;8:108-16.

6. Bindman $A B$, Grumbach $\mathrm{K}$, Osmond $\mathrm{D}$, et al. Primary care and receipt of preventive services. J Gen Intern Med 1996;11:269-76.

7. Pandhi N, DeVoe JE, Schumacher JR, et al. Preventive service gains from first contact access in the primary care home. J Am Board Fam Med 2011;24:351-9.

8. Pandhi N, DeVoe JE, Schumacher JR, et al. Number of first-contact access components required to improve preventive service receipt in primary care homes. J Gen Intern Med 2012;27:677-84.

9. Emilsson M, Berndtsson I, Lotvall $\mathrm{J}$, et al. The influence of personality traits and beliefs about medicines on adherence to asthma treatment. Prim Care Respir J 2011;20:141-7.

10. Jerant A, Chapman B, Duberstein P, et al. Personality and medication non-adherence among older adults enrolled in a six-year trial. Br J Health Psychol 2011;16:151-69.

11. Stilley CS, Sereika S, Muldoon MF, et al. Psychological and cognitive function: predictors of adherence with cholesterol lowering treatment. Ann Behav Med 2004;27:117-24.

12. Flory $\mathrm{K}$, Lynam $\mathrm{D}$, Milich $\mathrm{R}$, et al. The relations among personality, symptoms of alcohol and marijuana abuse, and symptoms of comorbid psychopathology: results from a community sample. Exp Clin Psychopharmacol 2002;10:425-34.

13. Terracciano A, Lockenhoff CE, Crum RM, et al. Five-Factor Model personality profiles of drug users. BMC Psychiatry 2008;8:22.

14. Terracciano A, Costa PT Jr. Smoking and the Five-Factor Model of personality. Addiction 2004;99:472-81.

15. Brummett BH, Siegler IC, Day RS, et al. Personality as a predictor of dietary quality in spouses during midlife. Behav Med 2008;34:5-10.

16. Mottus R, McNeill G, Jia X, et al. The associations between personality, diet and body mass index in older people. Health Psychol 2013;32:353-60.

17. Anderson CP, Ngo LH, Marcantonio ER. Complications in postacute care are associated with persistent delirium. J Am Geriatr Soc 2012;60:1122-7.

18. Chapman BP, Lyness JM, Duberstein P. Personality and medical illness burden among older adults in primary care. Psychosom Med 2007;69:277-82.

19. Jerant $A$, Chapman B, Duberstein $P$, et al. Effects of personality on self-rated health in a 1-year randomized controlled trial of chronic illness self-management. Br J Health Psychol 2010;15:321-35.

20. Terracciano A, McCrae RR, Costa PT. Intra-individual change in personality stability and age. J Res Pers 2010;44:31-7.

21. McCrae RR, Terracciano A. Universal features of personality traits from the observer's perspective: data from 50 cultures. J Pers Soc Psychol 2005;88:547-61.

22. McCrae RR, Costa PT Jr. Validation of the five-factor model of personality across instruments and observers. J Pers Soc Psychol 1987:52:81-90.

23. Hill EM, Gick ML. The big five and cervical screening barriers: evidence for the influence of conscientiousness, extraversion and openness. Pers Indiv Differ 2011:50:662-7.

24. Siegler IC, Feaganes JR, Rimer BK. Predictors of adoption of mammography in women under age 50. Health Psychol 1995:14:274-8.

25. Siegler IC, Costa PT Jr. Personality and breast cancer screening behaviors. Ann Behav Med 1994:16:347-51.

26. Brewer NT, Hallman WK. Subjective and objective risk as predictors of influenza vaccination during the vaccine shortage of 2004-2005. Clin Infect Dis 2006;43:1379-86.

27. Hauser RM, Sewell WH, Logan JA, et al. The Wisconsin Longitudinal Study: adults as parents and children at age 50 IASSIST Q 1992:16:23-38.

28. American Cancer Society. American Cancer Society guidelines for the early detection of cancer. Secondary American Cancer Society guidelines for the early detection of cancer March 5, 20082008. http://www.cancer.org/docroot/PED/content/PED_2_3X_ACS_ Cancer Detection Guidelines 36.asp

29. National Cholesterol Education Program. Detection, evaluation and treatment of high blood cholesterol in adults (Adult Treatment Panel III). Bethesda: National Institutes of Health. National Heart, Lung, and Blood Institute, 2002. 
30. Bridges CB, Harper SA, Fukuda K, et al. Prevention and control of influenza: recommendations of the Advisory Committee on Immunization Practices (ACIP). MMWR Recomm Rep 2003:52:1-36.

31. Agency for Healthcare Research and Quality. The pocket guide to clinical preventive services 2005. Rockville, MD: Agency for Healthcare Research and Quality, 2005.

32. John OP. The big five-factor taxonomy: dimensions of personality in the natural language and questionnaires. New York: Guilford, 1990.

33. Davies AR, Ware JE. GHAA's consumer satisfaction survey and user's manual. 2nd edn. Washington DC: Group Health Association of America, 1991.
34. Andersen RM. Revisiting the behavioral model and access to medical care: does it matter? J Health Soc Behav 1995;36:1-10.

35. Singleton JA, Poel AJ, Lu PJ, et al. Where adults reported receiving influenza vaccination in the United States. Am J Infect Control 2005;33:563-70.

36. Suter LG, Elmore JG. Self-referral for screening mammography. $J$ Gen Intern Med 1998;13:710-13.

37. Sutin AR, Zonderman AB, Ferrucci L, et al. Personality traits and chronic disease: implications for adult personality development. J Gerontol B Psychol Sci Soc Sci 2013;68:912-20.

38. Martin LM, Leff M, Calonge N, et al. Validation of self-reported chronic conditions and health services in a managed care population. Am J Prev Med 2000;18:215-18. 